\title{
Participação, eficiência e accountability no Brasil: desafios administrativos, políticos e institucionais
}

\author{
Participation, efficiency and accountability in Brazil: administrative, political and institutional challenges
}

La participación, eficiencia y responsabilidad en Brasil: retos administrativos, políticos e institucionales

BRUNO LAZZAROTTI DINIZ COSTA

Fundação JoÃo PINHEIRO, BELO HORIZONTE- MG, BRASIL

CeCíLIA OLIVIERI

Universidade de São Paulo / Escola de Artes, CiênCIAS E Humanidades, SÃo PaUlo - SP, Brasil

MARCO ANTONIO C. TEIXEIRA

Fundação Getulio Vargas / Escola de Administração de Empresas de São Paulo, Departamento de Gestão Pública, SÃo Paulo - SP, Brasil

Esta edição do periódico Cadernos EBAPE.BR tem por objetivo apresentar o desenvolvimento recente, as inovações e os desafios para a gestão pública nos três campos que têm experimentado mudanças institucionais e de gestão, frequentemente sobrepostos, apontando novas possibilidades e reiterando problemas persistentes: 1) participação; 2) eficiência; e 3) accountability. Organizamos os dez artigos em torno desses temas, sem nos arrogar a pretensão de cobrir toda a extensão da riquíssima produção que a área tem apresentado.

Uma das principais consequências da ampla experimentação e inovação institucional e de gestão no Brasil pós-Constituição de 1988 e pós-redemocratização é, a nosso ver, a importância de análises multidisciplinares. As dimensões técnicas e políticas, institucionais e gerenciais, vinculadas à democratização, à descentralização e ao controle público dos diferentes níveis do aparelho de Estado interpenetram-se e combinam-se de maneiras complexas o suficiente para escapar ao olhar ou a uma análise excessivamente disciplinar ou genérica. Os artigos aqui reunidos expressam essa pluralidade de enfoques disciplinares - sociologia, administração, ciência política, entre outros - e, também, de abordagens e estratégias de pesquisa, as quais contemplam revisão de literatura, discussão conceitual, mapeamento do campo, estudos de caso e combinações dessas abordagens.

Em relação à origem institucional dos autores, esta edição do Cadernos EBAPE.BR apresenta, ainda que involuntariamente, concentração de artigos provenientes de programas e instituições acadêmicas da região Sudeste, a despeito de as(os) autoras(es) apresentarem origem institucional e geográfica variada e da recente expansão do Campo de Públicas, com a abertura de cursos de graduação e pós-graduação nas regiões Norte e Nordeste na última década. Note-se, também, a predominância da filiação institucional em universidades e instituições acadêmicas em comparação aos órgãos da administração pública, o que expressa tanto a crescente relevância da área na comunidade acadêmica e universitária como a ainda distante articulação entre o debate acadêmico e reflexões, problemas e atores imersos no cotidiano da formulação, implementação e gestão de ações públicas. Superar o insulamento acadêmico e propiciar um debate mutuamente fecundo com servidores, técnicos e gestores públicos, sem comprometer a qualidade e o rigor teórico e metodológico próprios da produção acadêmica, é outro desafio de um campo de conhecimento que também é aplicado, embora não o seja exclusivamente. A administração pública é uma área da vida social e política que ainda carece fortemente de reflexão sistemática e que, por sua vez, produz inovação e esforços que nem sempre são percebidos ou incorporados pela academia.

É relevante apontar, também, a predominância de trabalhos sobre o Poder Executivo em relação aos outros poderes da República. É certo que há algo de natural nessa tendência, já que é responsabilidade precípua do Poder Executivo implementar e gerir políticas públicas, ainda mais em casos como o brasileiro, em que historicamente esse âmbito tende a concentrar o 
poderde agenda e recursos materiais e institucionais. No entanto, também há necessidade de aprofundar os estudos sobre a gestão pública no Poder Legislativo e no Poder Judiciário, por diversas razões: a crescente centralidade do Judiciário na vida política e econômica nacional; as controvérsias em torno dos custos e da eficiência do Judiciário e do Legislativo, bem como das dimensões normativas e morais da remuneração e das prerrogativas dos membros desses âmbitos diante de outras categorias de servidores; e, não menos importante, os desafios para a instituição e consolidação de práticas e mecanismos de transparência e accountability nesses poderes.

Ademais, a crise política que atravessa o Brasil indaga acerca de diversas questões, dentre elas o dilema (ou falso dilema) entre representação e participação. Nesse sentido, mais estudos a respeito da participação e de mecanismos de accountability sobre os representantes políticos no Poder Legislativo e no Poder Executivo tornam-se cada vez mais necessários, para pensar em novas ferramentas de aperfeiçoamento da democracia. Representação e participação se complementam e devem contribuir para o adensamento da legitimidade das decisões políticas. A discussão acerca da participação social no Legislativo, por exemplo, demanda uma agenda de pesquisa mais extensa, sobretudo porque o Congresso Nacional tem como fundamento a representação dos interesses dos cidadãos na produção legislativa e no controle das políticas públicas.

Os artigos sobre o tema participação são maioria e refletem a diversidade de objetos de pesquisa - política de esporte, cooperação para desenvolvimento, orçamento digital e gestão social -, bem como a pluralidade de enfoques analíticos no campo.

Os dois artigos que apresentam revisões da literatura sobre participação apontam a característica - ou será o dilema? - da prática de participação no Brasil das últimas décadas: a ampliação de esferas de participação criadas por ação ou iniciativa estatal, ainda que como reação a demandas sociais difusas ou organizadas. A partir desses textos, poderíamos perguntar se esse dilema é real ou apenas fruto de um viés analítico que privilegia o estudo das iniciativas estatais, o que não deixa de ser natural nesse campo.

O artigo "Inovações institucionais participativas: uma abordagem exploratória da produção brasileira em Administração Pública na RAP e no EnAPG (1990-2014)", de Ana Paula Paes de Paula e Tânia Margarete Mezzomo Keinert, apresenta um levantamento exploratório das inovações institucionais de caráter participativo na literatura brasileira recente sobre administração pública. A maioria dos 52 artigos analisados se refere à participação social e às políticas públicas participativas setoriais. Em frequência mais baixa aparecem os temas conselhos gestores, orçamento participativo e audiências públicas. As autoras concluem que o tema inovação institucional participativa tem sido tratado de forma difusa, pois, no caso dos artigos sobre participação social, destaca-se a participação como fenômeno novo no âmbito da administração pública, sem privilegiar sua institucionalização, e, no caso dos artigos sobre políticas públicas participativas setoriais, aborda-se a participação partindo das políticas públicas, o que enfatiza o protagonismo do Estado nessas iniciativas, na qualidade de promotor delas e não das inovações institucionais criadas por demandas sociais.

O artigo "Democracia e participação. Inovações democráticas e trajetória participativa no Brasil", de Tiago Ventura, apresenta interessante revisão da literatura sobre a relação entre democracia e participação no Brasil desde a proclamação da República, apontando o fortalecimento da participação a partir da redemocratização no final do século XX (anos 1980) e para as principais características do momento recente, em especial as três principais inovações participativas da última década: 1) criação de instrumentos mais transparentes de diálogo com a sociedade (potencialização das ouvidorias, uso de audiências públicas na condução de ações do governo e criação de mesas permanentes de negociação para dialogar com a sociedade civil); 2) forte impulso na constituição e no empoderamento de conselhos nacionais de políticas públicas com participação compartilhada entre Estado e sociedade civil na execução, na gestão e na consulta sobre as políticas; e 3) aumento exponencial de Conferências Nacionais de Políticas Públicas.

Os outros três artigos sobre o tema participação analisam casos que descrevem situações interessantes e desafios importantes para a participação democrática na gestão pública.

No artigo "Participação cidadã na formulação da política pública do esporte catarinense", Clerilei Aparecida Bier, João Paulo Bittencourt, Cauê Martins Franco e Clarissa Iser, mostram como o processo de participação na elaboração da política pública de esporte em Santa Catarina desenvolveu-se por meio da sucessiva expansão dos atores sociais participantes no Conselho Estadual de Desporto, criado em 1992 (o governo criou esse conselho e incentivou a ampliação da participação social em seu âmbito ao longo dos anos), e como esse processo foi refreado pelo próprio governo do estado, que, em 2003, reduziu 
o potencial de influência do conselho na elaboração da política ao promover uma reorganização administrativa que retirou atribuições das secretarias setoriais.

O artigo "Participação democrática em ambientes digitais: o desenho institucional do orçamento participativo digital", de Júlio Cesar Andrade de Abreu, também analisa um caso de promoção da participação democrática por parte do governo: a criação do orçamento participativo digital pela Prefeitura Municipal de Belo Horizonte. O estudo mostra como o desenho institucional do orçamento participativo digital favoreceu a ampliação quantitativa de participantes, já que criou a possibilidade de participação via internet, mas, ao mesmo tempo, limitou o potencial de debate democrático dessa ferramenta, uma vez que não permitiu a deliberação sobre quais obras seriam incluídas na consulta, mas apenas sobre quais obras, dentre as definidas pela prefeitura, seriam preferidas pela população.

Finalmente, o texto "Conflitos na gestão social do território: uma análise a partir da organização dos ilhéus em Porto Alegre", de Márcio André Leal Bauer e Rosinha da Silva Machado Carrion, também analisa um caso de organização para a participação social, mas com uma perspectiva diferente em relação aos outros dois trabalhos, pois não coloca a ação do governo como objeto principal da análise nem como motor da participação, mas sim a organização autônoma da comunidade. Essa organização ocorre em ambiente muito hostil, tanto por parte do governo como da opinião pública.

Ainda no tema participação, mas com um enfoque teórico, o artigo "Participação das organizações da sociedade civil na cooperação Sul/Sul: em busca de um modelo de análise nos estudos em administração", de Yasmine Santos Mansur e Armindo dos Santos de Sousa Teodósio, recorre a fontes bibliográficas de diferentes campos do conhecimento para entender as possibilidades, perspectivas e armadilhas que se configuram para os processos de cooperação para o desenvolvimento e que são moldadas pela busca de maior horizontalidade entre nações e participação de novos atores, notadamente da sociedade civil.

No tema eficiência e gestão, os artigos tratam de tópicos bem diversos. Dois deles apresentam análises da literatura, indicando, se não o amadurecimento, ao menos a difusão de estudos no Campo de Públicas, cuja quantidade já viabiliza pesquisas dessa natureza. $\mathrm{O}$ artigo "Capacidade institucional: uma revisão de conceitos e programas federais de governo para 0 fortalecimento da administração pública", de Fabiana Silva Fernandes, revisou o conceito de capacidade institucional, identificando que ele tem caráter polissêmico e pragmático e foi desenvolvido para mensurar e elaborar estratégias de fortalecimento da capacidade das instituições. $\mathrm{O}$ artigo "Fatores que moldam o comportamento dos burocratas de nível de rua no processo de implementação de políticas públicas", de Vicente da Rocha Soares Ferreira e Janann Joslin Medeiros, analisou a literatura que trata da atuação do burocrata de nível de rua no processo de implementação, identificando que seu comportamento é pautado por fatores pessoais, profissionais, gerenciais e políticos.

Ainda no tema eficiência e gestão, um dos poucos estudos que não abordam o Poder Executivo é o artigo "Medição da eficiência de magistrados e de unidades judiciárias no Ceará, Brasil: o sistema Eficiência.jus", de Leonel Gois Lima Oliveira, José Marcelo Maia Nogueira, Kátia Michelle Matos de Oliveira e Sérgio Mendes de Oliveira Filho, que analisa um Sistema de Apoio à Decisão que permite medir a eficiência de unidades judiciárias e de magistrados no estado do Ceará. Desenvolvido pelo Tribunal de Justiça do estado, esse sistema visa a auxiliar na tomada de decisões dos gestores e servir como um suporte objetivo nas promoções das carreiras dos juízes estaduais.

O tema accountability, a despeito de sua importância, dos avanços recentes e dos ainda grandes desafios, está representado nesta edição por um único artigo, que realiza um esforço de análise em âmbito nacional, bastante relevante considerando nossa situação federativa. "O papel das controladorias locais no cumprimento da Lei de Acesso à Informação pelos municípios brasileiros", de Maria do Carmo Meirelles Toledo Cruz, Thomaz Anderson Barbosa Silva e Mario Vinícius Spinelli, apresenta rico levantamento de dados sobre a gestão municipal em relação aos temas transparência e publicidade. Analisando as controladorias municipais, o artigo identifica que muitas cidades ainda não cumprem todos os requisitos da Lei de Acesso à Informação, que entrou em vigor em 2012, fragilizando a prestação de informações aos cidadãos.

Em suma, acreditamos que a diversidade de objetos e perspectivas analíticas e metodológicas da produção nacional no Campo de Públicas está bem representada nos dez artigos deste número temático do Cadernos EBAPE.BR. Esses estudos refletem o desenvolvimento das pesquisas em termos quantitativos e qualitativos e a evolução não apenas das experiências práticas, mas também da aprendizagem político-institucional de nossa gestão pública e de nossa democracia. 
Graduado em Ciências Sociais pela Universidade Federal de Minas Gerais (UFMG). Mestre em Sociologia e doutor em Sociologia e Política pela UFMG. Professor e pesquisador na Fundação João Pinheiro.E-mail: bruno.diniz@fjp.mg.gov.br

Cecília Olivieri

Graduada em Administração Pública pela Fundação Getulio Vargas de São Paulo (FGV/EAESP) e em Direito pela Universidade de São Paulo (USP). Mestre em Ciência Política pela USP e doutora em Administração Pública e Governo pela FGV/EAESP. Professora no curso de Gestão de Políticas Públicas da USP. E-mail: cecilia.olivieri@usp.br

Marco Antonio Carvalho Teixeira

Graduado em Ciências Sociais pela Pontifícia Universidade Católica de São Paulo (PUC-SP). Mestre e doutor em Ciência Política pela PUC-SP. Professor e pesquisador no Departamento de Gestão Pública da Fundação Getulio Vargas de São Paulo (FGV/EAESP). E-mail: marco.teixeira@fgv.br 